\title{
Rationale, design and methods for the 22 year follow-up of the Western Australian Pregnancy Cohort (Raine) Study
}

Leon M. Straker ${ }^{1 *}$, Graham L. Hall², Jenny Mountain ${ }^{3}$, Erin K. Howie ${ }^{4}$, Elisha White ${ }^{5}$, Nigel McArdle ${ }^{3}$, Peter R. Eastwood ${ }^{3}$ and the Raine Study 22 year follow-up Investigator Group

\begin{abstract}
Background: Young adulthood is a critical life period for health and health behaviours. Related measurements collected before and after birth, and during childhood and adolescence can provide a life-course analysis of important factors that contribute to health and behaviour in young adulthood. The Western Australian Pregnancy Cohort (Raine) Study has collected a large number of such measurements during the fetal, perinatal, infancy, childhood and adolescence periods and plans to relate them to common health issues and behaviours in young adults, including spinal pain, asthma, sleep disorders, physical activity and sedentary behaviour and, work absenteeism and presenteeism. The aim of this paper is to describe the rationale, design and methods of the 22 year follow-up of the Raine Study cohort.
\end{abstract}

Methods/Design: The Raine Study is a prospective cohort study. Participants still active in the cohort $(n=2,086)$ were contacted around the time of their 22nd birthday and invited to participate in the 22 year follow-up. Each was asked to complete a questionnaire, attend a research facility for physical assessment and an overnight sleep study, wear activity monitors for a week, and to maintain a sleep and activity diary over this week. The questionnaire was broad and included questions related to sociodemographics, medical history, quality of life, psychological factors, lifestyle factors, spinal pain, respiratory, sleep, activity and work factors. Physical assessments included anthropometry, blood pressure, back muscle endurance, tissue sensitivity, lung function, airway reactivity, allergic status, 3D facial photographs, cognitive function, and overnight polysomnography.

Discussion: Describing the prevalence of these health issues and behaviours in young adulthood will enable better recognition of the issues and planning of health care resources. Providing a detailed description of the phenotype of these issues will provide valuable information to help educate health professionals of the needs of young adults. Understanding the life-course risk factors of health issues and behaviours in young adulthood will have important health planning implications, supporting the development of targeted interventions to improve current health status and reduce the onset and development of further ill-health across adulthood.

Keywords: Longitudinal cohort, Life-course, Spinal pain, Asthma, Sleep, Sleep disorders, Activity, Work absenteeism, Work presenteeism, Chronic disease, Raine Study

\footnotetext{
* Correspondence: I.straker@curtin.edu.au

${ }^{1}$ School of Physiotherapy and Exercise Science, Curtin University, GPO Box U1987, Perth, WA 6845, Australia

Full list of author information is available at the end of the article
} 


\section{Background}

\section{The Raine study}

The Western Australian Pregnancy Cohort (Raine) Study is one of the largest, successful, prospective cohorts of pregnancy, childhood and adolescence to be carried out anywhere in the world. The participants, born between May 1989 and November 1991, have been assessed twelve times since their mothers were recruited at 16 to 18 weeks of pregnancy. As young adults, over $70 \%$ of the participants are still actively engaged in the study.

The Raine Study started as a randomised controlled trial to examine the effects of frequent and repeated ultrasound scans on pregnancy outcomes [1]. Pregnant women were recruited from the public antenatal clinic at King Edward Memorial Hospital (the sole tertiary women's and infant's hospital in Perth, Western Australia) and nearby private practice clinics. Only those booked into clinics before 18 weeks gestation were included, in order to reduce bias from those referred in late pregnancy due to complications [2]. The study collected questionnaire information at 18 and 34 weeks' gestation, in addition to ultrasound and Doppler information, mother and father information and pregnancy outcomes.

The Raine Study cohort was recognised as having great potential to inform developmental origins of health and disease [2] and, therefore, initial consent sought approval for long term follow-up. From the 2,900 women enrolled into the study there were 2,868 live births from 2826 mothers. The children have had data collected at 1 , $2,3,5,14,17,18,20$ and now 22 years of age. Available data cover a wide range of health and behaviour variables, reflecting the diverse research issues previously investigated. Currently, over 85,000 phenotypic, behavioural and environmental variables are available for each participant, along with an extensive genetics database. Biological samples were obtained from participants at many of these time points. The Raine cohort is well established and there is frequent contact between enrolled families and study organizers. A representative group of cohort members participates in ongoing discussions about research in the cohort.

\section{Young adulthood a critical period for health and related behaviours}

The focus of the Raine Study has evolved from a 'developmental origins' approach to a 'life-course' approach, to allow investigation of the health and behaviours of the cohort in young adulthood and beyond, and to examine both accumulated risk and critical risk periods [3, 4]. Young adulthood is recognised as a critical life phase for health [5], and for physical and mental development [5, 6]. Young adulthood is a transitional time when health behaviours impact on adult lifestyle habits [5]. Young adults are at greater risk for health impacts and health outcomes than adolescents [7].

With Raine Study participants turning 22-23 years of age, five focus areas received funding for further, indepth assessment: spinal pain, asthma, sleep and its disorders, physical activity and sedentary behaviour, and work productivity. These are important health-related issues, currently under-researched among young adults, which are likely to be influenced by early life factors and thus be informed by a life-course approach where rich pregnancy, perinatal, infancy, childhood and adolescent data are available.

\section{Spinal pain \\ The importance of spinal pain}

Back pain and neck pain are, respectively, the 1st and 4th most common reasons for years lived with a disability [8]. One month prevalence for either back or neck pain has been estimated at $13-50 \%$ in adults [9]. For the individual with disabling spinal pain the burden is substantial, including the experience of pain, restricted work/leisure activity, reduced quality of life, impaired general health and associated comorbidities such as anxiety and depression [9]. Back pain and neck pain both result in substantial financial costs for society through direct healthcare costs plus lost productivity. For example, back pain is one of the most expensive health care problems internationally [9]: in Australia for 2001, estimated costs were over $\$ 474$ per capita [10].

\section{Early life predictors of spinal pain in young adults}

Contrary to popular belief, adolescents can experience disabling spinal pain [11]. While there is some limited evidence that the experience of spinal pain during adolescence increases the risk of spinal pain in adulthood [12], there is also a belief that adolescent spinal pain is transitory and part of normal development [13]. There is growing evidence to suggest that shared early life factors increase the risk of developing pain in later life $[14,15]$ including genetic and environmental factors. Life stress events, poor family functioning, low socioeconomic status, sleep disturbances, depression and anxiety potentially alter the function of the HPA axis leading to altered pain processing and increased stress sensitivity [16]. Factors such as high levels of adiposity, altered body postures and muscle deficits may interact with activity patterns, potentially, to promote repetitive strain on pain sensitive structures $[14,17]$. These biopsychosocial factors develop in early life and may set risk trajectories for disabling spinal pain in adulthood [17]. Whilst several, longitudinal studies have identified biopsychosocial factors in adolescence which predict adult spinal pain $[12,15]$, the majority of studies has been unidimensional. To date, there are no pregnancy and birth 
cohort studies investigating vulnerability to disabling spinal pain in adulthood across the entire life-course.

\section{Limited information about spinal pain disorders in young adults}

Disability relating to spinal pain has been reported to be the most common cause of activity limitation below the age of 45 [18]. Despite this, there is very limited information about disabling spinal pain in young adults. A recent study reported that low back pain disability levels were constant between the ages of 20-40 years, although the 20-29 year age group were under represented in the study [19]. Disabling low back pain has also recently been identified in a small cohort study of young female nurses (mean age 22, $n=199$ ) suggesting the behaviours associated with disabling low back pain may already be developed in adults in their early 20s [20]. Currently, there is no investigation of disabling spinal pain in young adults who are representative of the broader community. Additionally, it is not clear whether disabling spinal pain in adolescence tracks through to adulthood. This knowledge gap is critical [17] as it is not known whether adolescent and adult disabling spinal pain disorders are separate entities or part of an emerging disabling spinal pain vulnerability that develops in early life.

Despite the enormous cost, the prevention and management of disabling low back pain remains largely ineffective [21], with studies examining prevention interventions typically finding no positive effect [21]. Leading researchers have called for a cessation of all RCTs into managing spinal pain until there is a better understanding of key aspects of spinal pain including the life-course development, multi-dimensional characterisation and potential heterogeneity of the disorder $[22,23]$. A well-characterised, longitudinal cohort, such as that in the Raine Study, is required to enable investigation into the multi-dimensional life-course risk factors and development of disabling spinal pain, and adequate capture of the multi-dimensional characteristics and potential heterogeneity of disabling spinal pain.

\section{Asthma}

\section{The importance of asthma disorders}

Asthma is a chronic airways disease characterised by airway inflammation, recurrent respiratory symptoms, airway reactivity and airway obstruction that is at least partially reversible. According to the World Health Organisation, asthma affects over 235 million people and results in over 200,000 deaths each year, worldwide $[24,25]$. Asthma is a heterogeneous disease and includes multiple phenotypes, with differing underlying disease pathogeneses, commonly recognised phenotypes include allergic asthma, non-allergic asthma, late-onset asthma, and asthma with obesity [26].

\section{Early life risk factors for asthma}

It is increasingly evident that lung function tracks into adult life [27], suggesting that environmental exposures (including maternal nutrition, environmental tobacco smoke, respiratory infections and allergen exposure) [28] in early life play a significant role in the development of chronic respiratory disease in adults. There is also emerging evidence that chronic obstructive pulmonary disease is linked to asthma in childhood [7, 29], further highlighting the importance and necessity of a true life course approach to the investigation of chronic respiratory diseases, such as asthma. Examples of the value of a life-course approach to understanding asthma can be seen in the following findings from the Raine and other cohort studies: (i) maternal nutrition and micro-nutrition and slower fetal growth is associated with lower lung function and increased atopy (predisposition to allergy), wheeze and asthma in childhood, [30,31] and increased airway reactivity in adolescence [32]; (ii) wheezing and lower respiratory illness (LRI) in early life and atopy are independently associated with current asthma at 6 years [33]; (iii) recent wheeze and airway reactivity during childhood are independently associated with reduced lung growth during adolescence [34]; (iv) young adults with asthma have lower lung function than their healthy counterparts at age 19 and there is an accelerated decline in lung function in these individuals [35]; (v) prenatal growth is one potential risk factor linked to immunological development, which is related to long-term trends in airway reactivity and lung function $[27,36]$.

The persistence of asthma through childhood and into adult life is common in atopic individuals with low lung function and airway reactivity [37], however, these relationships are not always evident which suggests as yet unknown modifying pathways may be involved. Data from the Raine Study at the 14 year follow up reported that $\sim 50 \%$ of the atopic asthmatics did not demonstrate airway reactivity [38]. Furthermore, atopic asthmatics without airway reactivity had significantly lower total and house dust mite specific IgE levels compared with atopic asthmatics with airway reactivity. These data suggest a threshold level of specific IgE beyond which atopic individuals begin to display symptoms and airway reactivity. This observation has been extended by studies suggesting that the asthma-associated phenotypes in children with indoor allergen specific IgE are attenuated by IgG of the same specificity [39]. The mechanisms for these interactions in childhood or their roles in asthma in later life are not clear. However an underlying mechanism is likely to be age-dependent "maturation" of relevant elements of the host response to allergens, which probably includes changes in relative IgE and IgG titres and in antibody affinity, both of which are known to change progressively with continuing exposure. 
Despite our wealth of knowledge on the risk factors associated with childhood asthma, our understanding of the life course of asthma is limited. Longitudinal birth cohort studies, such as the Tucson Respiratory study and the Raine Study, are uniquely poised to contribute to knowledge of the persistence of asthma throughout childhood and into the early adult years, as well as to further our understanding of the risk factors associated with the development of late-onset asthma in young adults.

\section{Limited information about persistent versus late-onset asthma in young adults}

Atopy in childhood, along with concomitant low lung function, airway hyper-responsiveness and being female have consistently been linked to the persistence of asthma from childhood to early adult life. It is likely that a range of immunological, physiological and environmental factors contribute to an individual's risk for the development of asthma in young adults, in addition to development of chronic obstructive pulmonary disease in later life [40, 41]. While longitudinal studies of clinical asthmatics (such as the Melbourne Asthma study [42]) provide a wealth of information on factors associated with the persistence and long-term implications of asthma, they are unable to offer insights into the factors associated with onset of asthma after puberty. The factors associated with the onset of asthma post-adolescence are not well understood. In contrast, longitudinal, populationbased birth cohorts, such as the Raine Study, are able to determine the impact of lung function, AHR, atopy, and environment not only on the persistence of asthma throughout childhood and into the adult years, but also on the development of asthma and chronic obstructive pulmonary disease in early and later adult life.

\section{Sleep disorders}

\section{The importance of sleep disorders}

Clinically significant obstructive sleep apnoea (OSA) is a common condition occurring in $1-2 \%$ of children [43-45] and 2-4\% of the middle-aged population [4648]. It is caused by repetitive, upper airway obstruction due to collapse of upper airway structures during sleep. Obstructive respiratory events are accompanied by repetitive oxygen desaturation and blood pressure surges, and are usually terminated by brief awakenings (electroencephalographic arousals). OSA impairs daytime function and is associated with major reductions in quality of life $[49,50]$, increased risk of motor vehicle accidents [51] and cardiovascular disease; including hypertension, cardiac failure and stroke and an increase in all-cause mortality [52-54].

\section{Early life predictors of sleep disorders in young adults}

It is crucial to understand the early life, developmental and environmental influences predisposing to abnormal breathing during sleep as many individuals are asymptomatic, yet still at increased risk of metabolic and cardiovascular disease. Unfortunately, there is a paucity of data exploring early life influences on the development of OSA and on the trajectories of obesity that lead to OSA. It is highly likely that these influences commence in utero and are further influenced by early life environmental exposures.

In children, there are substantial, cross-sectional data on risk factors for OSA, including prematurity [55] and maternal smoking [43], but few longitudinal studies [55]. Although adenotonsillar hypertrophy has, historically, been the predominant OSA risk factor in children, recent data show that BMI represents a new, important risk factor, with OSA risk increased by a factor of 3.5 for each standard deviation increase in BMI z-score [56]. Notably, the increased risk appears to commence in the adolescent years (age $\geq 12$ years). Research undertaken in other fields has shown there may be critical periods in childhood where growth patterns and weight gain have strong influences on adult health outcomes [57, 58]. Recognition of perinatal risks predisposing to the subsequent development of OSA may allow anticipatory screening to prevent the development of adverse consequences.

In a Swedish cohort of 4 year old children, parental reports of restless sleep and mouth breathing were strongly associated with habitual snoring [59]. Further, habitual snorers had cephalometric changes including a narrower maxilla [59]. Hence, there appear to be early markers of obstructive sleep disordered breathing and early anatomical changes which may predispose to OSA later in life. The Raine cohort has collected parental reports of sleeping behaviours in the first few years of life which will help address the relationship between infant sleep behaviours and subsequent development of OSA in adulthood.

\section{Limited information about sleep disorders in young adults}

The prevalence of OSA in young adults is unknown. This is due to a paucity of prevalence studies undertaken in this age group, as the focus to date has been almost exclusively on children $[44,45,55]$ and cross-sectional studies among middle aged-adults [46-48, 52, 60], with few population-based studies with longitudinal follow-up of the natural history of OSA $[52,60]$. The age ranges of most OSA prevalence studies, to date, are shown in Fig. 1 [43-48, 55, 59-79], which illustrates the focus to date on children and middle-aged and elderly adults. Despite using gold-standard methods (e.g. laboratory PSG in all or a subset of patients) studies have revealed considerable 
variability in OSA prevalence estimates for middle-aged men $(1.2 \%$ [61] to $19 \%$ [62]) and women (1.2\% [80] to $15 \%$ [62]). While these data have raised awareness of the high prevalence of undiagnosed disease [81] and the need for adequate consideration in terms of healthcare policy and research funding, the natural history of the disease remains poorly understood and disease onset and progression are largely unknown. Similarly, there are no data on the phenotype of OSA in young adults, which may differ from middle-aged individuals. Nor are there data on the early life risk factors for developing OSA in adulthood, including obesity.

\section{Physical activity and sedentary behaviour The importance of physical activity and sedentary behaviour}

Too little exercise (insufficient moderate/vigorous physical activity) is estimated to be the leading, modifiable cause of health burden in Australia, after tobacco [82]. Coupled with this, is the rapidly accumulating evidence that too much sitting (excess sedentary behaviour) is detrimentally associated with health, even in adults who undertake sufficient exercise for health benefits [83]. Taken together, these behaviours create an increasing burden of substantial public health concern [84].

Detailed, objective, international analyses have found that fewer than $10 \%$ of adults achieve at least $30 \mathrm{~min}$ of moderate/vigorous physical activity accumulated in bouts of at least $10 \mathrm{~min}$ on at least 5 out of 7 days [85,
86]. This 'inactivity' has significant public health consequences. The World Health Organization has identified inactivity as the fourth largest global risk factor for mortality, causing an estimated 3.2 million deaths worldwide each year [87]. In Australia, inactivity has been estimated to cost the economy $\$ 14$ billion annually [88].

There is now consistent and compelling evidence that time spent in sedentary behaviours as adults, independent of physical activity, is associated with all-cause mortality [89], cardiovascular disease [89], obesity [90], adverse metabolic profiles [91], and poor fitness in later life [92]. Importantly, associations remain even after adjusting for moderate/vigorous physical activity exposure [90, 93]. Recent evidence indicates that the adverse effects of sedentary behaviour are present in childhood [94], even in the early years [95], suggesting that understanding the lifecourse predictors of these behaviours is critical.

Furthermore, patterns of sedentary time accumulation are also important. Extended periods of uninterrupted sedentary time have been related to poor metabolic profiles in middle aged Australian adults (Australian Diabetes, Obesity and Lifestyle Study (AusDiab study) [93]), and to cardiometabolic and inflammatory biomarkers in American (USA) adults (National Health and Nutrition Examination Survey (NHANES) cohort [96]). There is also evidence that light intensity activity, independent of moderate/vigorous physical activity, has important health benefits [97]. A recent study has also shown that light activity and sedentary

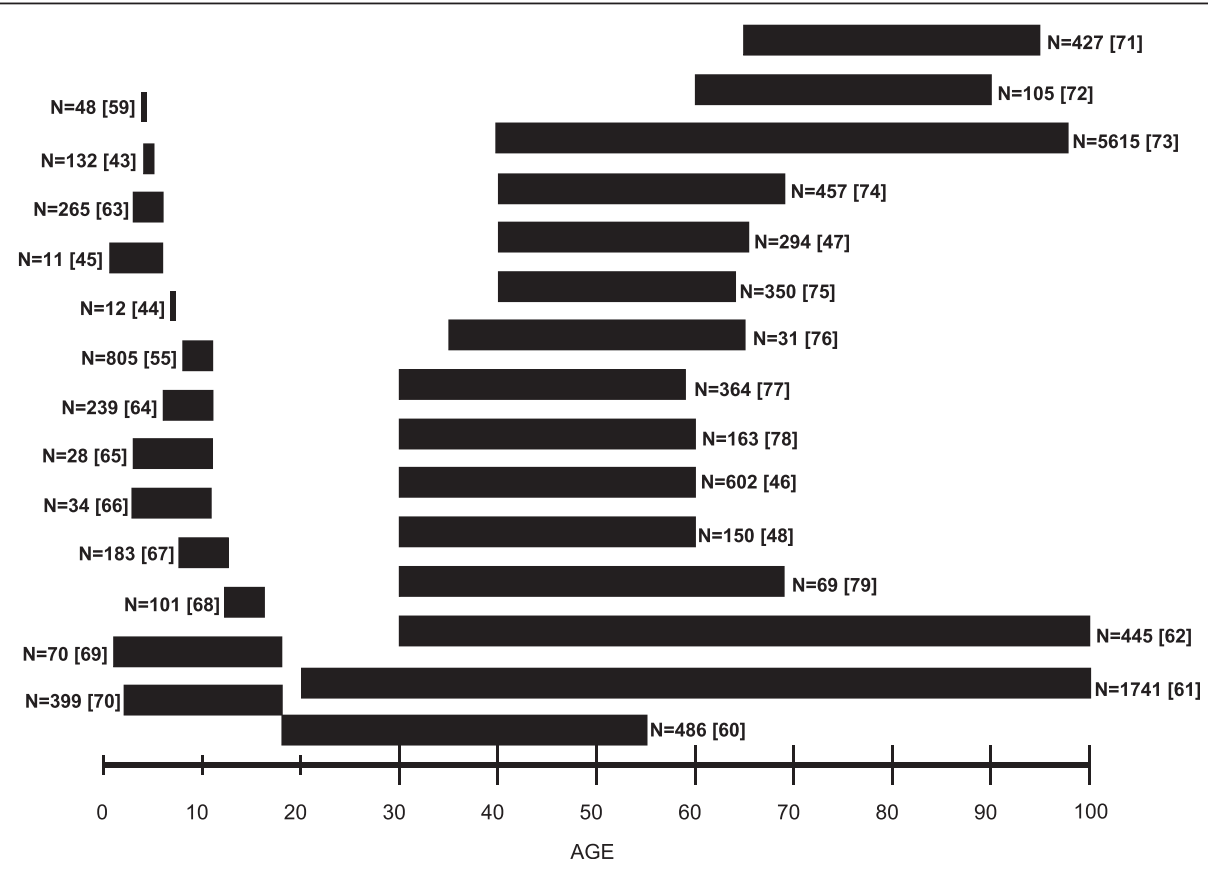

Fig. 1 Obstructive sleep apnea prevalence studies, to date, showing the age range and sample sizes of study cohorts 
time are highly negatively associated [97]. Thus, the whole spectrum of movement intensity, from sedentary through to vigorous, appears important to help prevent chronic disease and understand its development.

\section{Limited information about sedentary behaviour in young adults}

The sedentary behaviour habits of young adults (20-25 years) are largely unknown. This is due to a paucity of objective studies of sedentary behaviour undertaken in this age group, as the focus to date has been almost exclusively on children, middle-aged adults and elderly adults. No study has explicitly focused on the early adult years. The few studies with objective measures, that have included a proportion of young adults, have been quite broad in their age division categories: $20-30$ years in the NHANES cohort from the USA [98]; 20-35 years in Belgium [99]; and 20-39 years in Canada [86]. Such age ranges limit the ability of these studies to inform influences on sedentary behaviour in young adults. Whilst the ongoing, longitudinal AusDiab study [93, 97] has included 25 year-olds at baseline, there were no objective measures obtained at this time point. Inactivity patterns vary with age and are influenced by different factors at different ages [100]. Therefore, there is a need for a focus on specific age ranges - in particular the critical period of young adulthood. Yet, thus far, there are no longitudinal studies utilizing life-course biological, psychological, social, behavioural and context variables to predict physical inactivity and sedentary behaviour in young adults. The Raine Study has a wealth of longitudinal early life predictors that may help explain the amounts and patterns of objectively measured physical activity and sedentary patterns among young adults.

\section{Early life predictors of physical activity and sedentary behaviour in young adults}

In order to develop interventions to promote physical activity and reduce sedentary behaviour in young adults, insight into determinants of these behaviours is necessary. However, much of the available evidence comes from cross-sectional studies. This has resulted in calls for high quality, prospective evidence [101]. Most early studies on health behaviour determinants have been informed by psychological theories of human behaviour with a strong focus on cognitive determinants [102]. More recent research has used a social-ecological framework [103] which acknowledges the importance of the environments in which people live. Contemporary models from ergonomics [104], occupational health [105], sedentary behaviour [101] and life-course epidemiological [106] fields also incorporate earlier sociotechnical systems and biopsychosocial models, thereby acknowledging the importance of individual characteristics and their interaction with other system elements which influence behaviours within a context over time. Adult research suggests many potential determinants of inactivity and sedentary behaviour including biological, physiological, and social factors. Determinants may be from occupation, transport, household and leisure contexts. However, there is limited similar research in young adults. Figure 2 represents a synthesis of these models as a framework for the Raine Study.

\section{Work productivity \\ The importance of young worker productivity}

Productivity, along with increased supply of capital and labour, drives economic growth. The importance of productivity to the nation goes beyond purely economic terms [107] given it is a determinant of social welfare status [108], contributes to funding of societal institutes (e.g. law and order) [109], drives long-term prosperity [110] and ensures ongoing improvements in standard of living.

The aging population, both globally and in Australia, is placing and will continue to place greater burden on workers [111]. For example, it is projected that by 2056 there will be a 3:1 ratio of working adults for every older person, in contrast to the present ratio of 5:1 [112]. Young Australians (20-34 years) currently constitute the largest proportion of the civilian labour force (22\%) [113]. While Australian Government strategy has focused on increasing workforce participation in target groups (the aged, mothers, non-working males of working age) and through immigration [111], there will be growing pressure on younger workers to increase their productivity to support Australia's standard of living. The importance of young workers will continue to increase into the future, as the (positive or negative) attributes of their productivity accumulates over a lifetime of workforce participation.

Health has been recognised as a key contributor to productivity [108]. Weil [114] estimated a worker in good health in a low mortality country would be about $70 \%$ more productive than a worker suffering from ill health in a high mortality country. Additionally, major contributors to presenteeism were depression (21\%), allergies (17\%), hypertension (13\%), diabetes (12\%), spinal pain (7 \%) and asthma (7\%) [115]. Bloom [116] concluded that 'health is a vitally important form of human capital and deserves the same level of attention...as is currently paid to the accumulation of physical capital and education." However, such considerations have been given limited attention.

Young workers are a key productivity resource now and into the future. Strategies to increase younger worker productivity have focused on education, training and transition into the workforce [117]. There is a common 


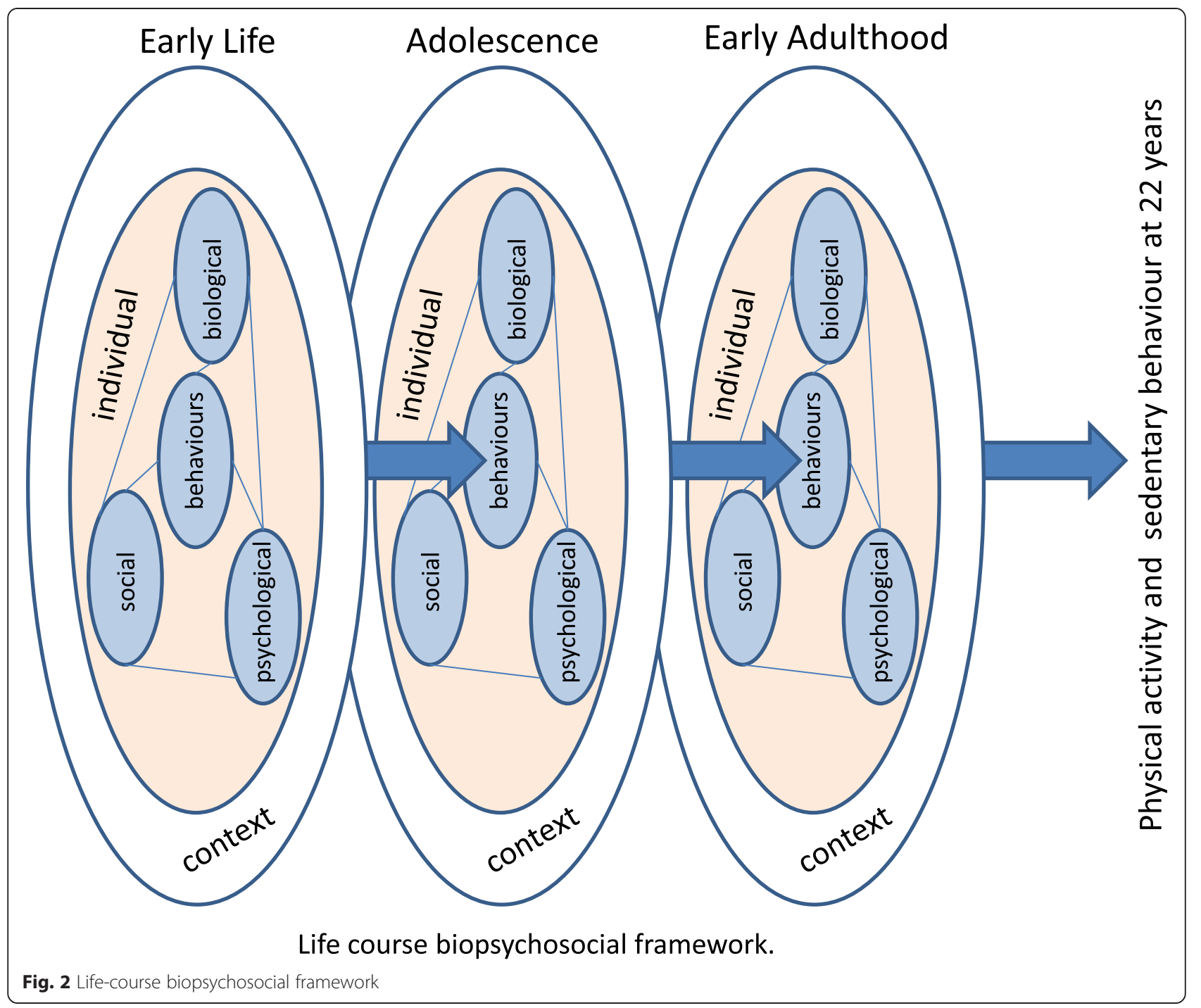

perception that health may not be a major problem for young workers, compared to older workers. However, young adults in Australia have a high prevalence of conditions such as spinal pain (15\%) [118], sleep problems (26\%) [119] and mental health disorders (26\%) [118] as well as poor health behaviours such as alcohol misuse (27-32 \%\%) [120]. These common health problems affecting young adults are all known negatively to impact on work productivity [121-123].

\section{Limited information on young worker productivity}

Absenteeism (absence of an individual from work) is the commonly used measure of the quantity of productive time lost. Presenteeism (reduction in productivity while an individual remains at work) is increasingly being recognised as a critical component in productivity loss as it deals with the quality of productive time. Since presenteeism is estimated to result in 3 to 7 times the productivity loss of absenteeism [124] and health conditions typically have a much greater impact on presenteeism than absenteeism $[122,125]$ it is essential that presenteeism be included in any modelling of healthrelated work productivity loss.

Given the importance of young worker productivity, a robust estimate of the magnitude of health related work productivity loss is critical. Current worker's compensation data suggest musculoskeletal and mental health disorders are important conditions for young worker productivity loss as they account for $80 \%$ of serious absenteeism claims (from 2008-09) [126]. However, no data on the full, work productivity loss for young workers across the range of common health conditions have been reported. Whilst several countries monitor national workers' compensation absenteeism figures, 
there are concerns that those data present a biased estimate. Specifically, young workers underreport problems due to a range of reasons including potential negative impact on employment, lack of leave entitlements and lack of knowledge of rights and reporting systems [127, 128]. Australian Bureau of Statistics (ABS) data show only $38 \%$ of injured workers under 25 years of age applied for compensation [127]. The Raine cohort provides an unbiased sample where data on health related productivity loss can be collected in a robust and prospective manner.

Knowing the size of the problem of health related work productivity loss in young workers, and which health conditions contribute most, is important. However, a clear understanding of what young workers with high and low productivity 'look' like is needed, to encourage high productivity and address low productivity. Modifiable health disorders such as back/neck pain [129], psychological distress [122], workplace injury and obesity [130] are all known to increase the risk of absenteeism and presenteeism. Health related lifestyle factors/behaviours such as sleep [123], physical activity [121] and drug use [122] also have a significant impact on work productivity. Importantly though, the prevalence of disorders [118] and health behaviours [131] varies with age. Despite this, health conditions and lifestyle factors profiles of high and low productivity young workers are not known.

\section{Early life predictors of health related work productivity loss in young workers}

Little is known about the relationship between early life health factors and young worker productivity. Childhood health appears to play a role in adult workforce participation [132] while childhood poverty is a predictor of reduced productivity later in life [133]. Further, spinal pain [134] and mental health [135] problems frequently develop in early life and track into adulthood. Thus, pre-adult factors may be important to young worker productivity. The Raine Study cohort provides a unique opportunity to examine these relationships, as it is not only representative of 22 year old adults, but also has an unparalleled richness and breadth of health related data spanning pre-birth to adulthood.

\section{Aims}

The Raine Study 22 year follow-up had the following aims:

1. To describe the prevalence of critical health issues and behaviours in young adulthood;

2. To characterise the phenotypes of critical health issues and behaviours in young adulthood; and,
3. To evaluate the gestational, childhood and adolescent risk factors for critical health issues and behaviours in young adulthood.

\section{Methods}

\section{Study design and sample}

The study design was a prospective follow-up of an established pregnancy cohort at age 22 to 23 years. The study sample consisted of all active members of the cohort ( $n=2,086$ or $72.7 \%$ of the original cohort of 2,868 ), that is those who had previously provided consent to be contacted for follow-up and were not deceased $(n=40)$, had not withdrawn $(n=566)$, or otherwise been lost to follow-up $(n=176)$.

\section{Ethics approvals}

Approval for the 22 year follow-up was obtained from the Human Research Ethics Committees at the University of Western Australia (RA/4/1/5202) and Curtin University (HR67/2013). The study was conducted in accordance with the Declaration of Helsinki and informed consent was obtained from all participants.

\section{Measures}

\section{Spinal Pain}

Pain questionnaire Pain location, frequency, duration and intensity assessment was assessed with the Nordic Questionnaire which has demonstrated reliability and validity [136], with modifications based on subsequent research [137-139]. The impact of spinal pain on daily activity and physical activity, as well as on health care use, medications taken, health professionals visited [140] and work/study days lost [141] was also be assessed.

Back muscle endurance Participants completed a prone trunk hold, the Biering-Sorenson test [142], which has high reliability in young people [143] and displays good validity [144].

Tissue sensitivity Pain thresholds to both pressure and cold were collected using standard protocols [145]. Following sensation checks, pressure pain thresholds were tested 4 times on each location (right wrist, neck, leg and lumbar spine) using a Somedic digital algometer. Cold sensation threshold testing followed by cold pain threshold was tested 4 times on the dorsal aspect of the right wrist using a Somedic thermal stimulator.

\section{Asthma}

Previous and current respiratory symptoms and allergy information were assessed by validated, standardised questionnaires. Lung function was assessed by spirometry and the forced oscillation technique, and airway hyper-responsiveness to an inhaled mannitol challenge 
was also performed. Airway inflammation was assessed by exhaled nitric oxide and cellular studies were undertaken from induced sputum. Atopy to a range of common aeroallergens was assessed with skin prick tests complimented by measurement of total and specific IgE titres from serum samples. Participants were requested to withhold antihistamines and all asthma medications for $72 \mathrm{~h}$ prior to testing, and were questioned to verify medication withholding on the day of testing.

Respiratory questionnaire Current, recent and previous respiratory and allergic symptoms and disease were assessed, using validated questionaries modified from the International Study of Asthma and Allergy in Children (ISAAC) [146] and based on those utilised by previous Raine Study follow-ups [32, 147] and the Busselton Healthy Ageing Study [35].

Spirometry Spirometry was measured as per international guidelines [148] using a KOKO spirometer (inSpire Health Inc. USA) and FVC, FEV 1 , FEV1/FVC and $\mathrm{FEF}_{25-75}$ reported. Data were reported as both absolute and predicted values (expressed as z-scores) derived from the Global Lung Function for Spirometry reference ranges [149] the validity of which has been confirmed in a contemporary Australasian population [150].

Forced oscillation The mechanical impedance of the respiratory system (Zrs) was measured with the modification of the FOT [151]. Briefly, a small-amplitude signal between 4 and $26 \mathrm{~Hz}$ was delivered to the subject through a mouthpiece via a low-deadspace wave tube. Averaged Zrs spectra in each subject were used to obtain total respiratory resistance and compliance. In addition to average values, the within-breath changes in Zrs, as functions of tidal volume and flow, during tidal breathing and during a slow inspiration to total lung capacity were also determined.

Airway hyper-responsiveness The mannitol challenge (Pharmaxis Ltd, Frenchs Forest, NSW, Australia) test protocol consisted of inhalations of control (empty capsule) and increasing doses of mannitol to a maximal cumulative dose of $635 \mathrm{mg}$, per standard guidelines [152]. After each dose, subjects were instructed to expectorate any sputum present into a Petri dish. Inhalation of successive doses continued until the last dose was taken, or a positive response recorded. A positive response was defined as a $10 \%$ fall in $\mathrm{FEV}_{1}$ between doses, or a $15 \%$ fall from baseline $\mathrm{FEV}_{1}$ (PD15). Responsiveness was defined using the PD15 and the dose response slope.

Exhaled nitric oxide Exhaled nitric oxide was measured as a surrogate for airway inflammation. Briefly, subjects were seated and asked to inhale NO-free air to total lung capacity and immediately to exhale through a mouthpiece, according to international guidelines [153]. Flow was maintained at $50 \mathrm{~mL} / \mathrm{s}$ using a feedback system displayed by the equipment software (Ecomedics, Switzerland). A minimum of 3 acceptable measurements that varied by less than $10 \%$ were obtained.

Induced sputum Sputum samples were obtained during the mannitol challenge test, as described above and reported previously $[154,155]$. Within $2 \mathrm{~h}$ of collection the pooled sputum sample was dispersed with Sputolysin (Calbiochem) and total and differential cell counts made from stained cytospin slides, per international guidelines $[156,157]$. CD45+ cells were selected using Dynabeads (Dynal), resuspended in RNALater (Ambion) for preservation of nucleic acids and stored at $-20{ }^{\circ} \mathrm{C}$ for future studies. Any remaining sputum fraction was cryobanked for future metagenomic studies to examine bacterial colonisation of the airways.

Blood collection A $100 \mathrm{ml}$ sample of peripheral blood was collected into a tube containing preservative-free heparin and processed within $2 \mathrm{~h}$. Plasma was isolated and aliquots stored at $-80{ }^{\circ} \mathrm{C}$ for measurement of antibodies and for future studies. Following removal of plasma, peripheral blood mononuclear cells were isolated within $18 \mathrm{~h}$ of this step using Lymhoprep. After counting, peripheral blood mononuclear cells were suspended in medium to $16 \times 10^{6}$ cells $/ \mathrm{ml}$, and $0.5 \mathrm{ml}$ aliquots prepared for cryopreservation and storage in a monitored gas phase liquid nitrogen storage tank. A single aliquot of whole blood was processed for a full blood count, including circulating eosinophils, neutrophils, macrophages, basophils and lymphocytes.

Skin prick testing Skin prick testing was performed according to local guidelines [158]. Allergens used were: Cat fur and pelt, dog hair, dust mite-Dermatophagoides farinae, dust mite-Dermatophagoides pteronyssinus, perennial rye grass, grass mix, American cockroach, Alternaria Tenuis, Aspergillis Fumigatus, whole cow's milk, egg white, Histamine Hydrochloride $10 \mathrm{mg} / \mathrm{ml}$ positive control, and glycerine/saline negative control. The length and widths of each resulting wheal for each allergen and the controls was recorded. A positive result indicating sensitisation was defined for each wheal that exceeded the negative control by $>3 \mathrm{~mm}$ [32].

\section{Physical activity and sedentary behaviour}

Accelerometers Tri-axial Actigraph GT3X+ monitors (Florida, USA) were used to capture date and timestamped activity data. These portable lightweight (19 g; $4.6 \times 3.3 \times 1.5 \mathrm{~cm})$ water resistant accelerometers 
collected movement data in raw format, allowing a range of sophisticated analytic options. The GT3X+ is currently being used in other major studies, thus use of this device enabled direct comparison with other datasets.

Data collection and analysis protocols follow best practice guidelines [159]. Participants were asked to wear two GT3X+ accelerometers continuously ( $24 \mathrm{~h}$ per day) on the right hip and non-dominant wrist for eight consecutive days, with the raw data collected at $30 \mathrm{~Hz}$. Sleep times, work times, and any removal times were recorded in a diary.

Initially, data from the vertical axis (equivalent to the previous GT1M Actigraph model -[160]), exported as $60 \mathrm{~s}$ epoch files, were used to derive key sedentary and inactivity measures across the whole day and during specific periods, such as work, and on weekends and weekdays. Time spent being sedentary $(<100$ counts per minute, cpm), in light-intensity activity (100-1951 cpm), and in moderate-to-vigorous intensity activity (>1951 cpm: MVPA) was considered. Similar, triaxial assessments will also be generated in the future [160]. Non-adherence to physical activity recommendations (achievement of $30 \mathrm{~min}$ of MVPA on at least 5 out of 7 days accumulated in bouts of $10 \mathrm{~min}$ or more [85] and the proportion of wake time spent in sedentary activity were determined. Patterns of sedentary time and MVPA were assessed with examination of bouts, including 10-min bouts of MVPA and prolonged bouts ( $>20 \mathrm{mins}$; $>30 \mathrm{mins}$ ) of sedentary time, as well as the number of breaks in sedentary time (the number of transitions between a sedentary $(<100 \mathrm{cpm})$ and active ( $\geq 100 \mathrm{cpm})$ time) [91].

Activity questionnaire Time spent in physical activity and sitting, and in specific sedentary behaviours (e.g. computer use, television time) was assessed using the short form of the International Physical Activity Questionnaire [72] and Raine Study standard questions based on the Kaiser Family Foundation USA national survey [161] and the Young People's Activity Questionnaire [162].

\section{Health related work productivity}

Work productivity loss At 23 years of age was prospectively captured using the World Health Organisation's recommended Health and Productivity Questionnaire (HPQ) [163]. The HPQ provides separate estimates of both absenteeism and presenteeism over the previous 4 week period for any health reason. Given inconsistencies in organisational data, self-report of absenteeism and presenteeism is the preferred method to enable consistent estimates across a community cohort and account for multiple, part-time and casual employment: an important consideration for younger workers. The HPQ has also demonstrated good one week test-retest reliability $(r=0.89)$ [164]. The scale has been used in around 30 countries and has an international master database of benchmark data. Absenteeism is presented as hours lost per month for each worker, from which an annualised estimate can be made. Validation studies show HPQ self-reports of absenteeism have good concordance with payroll records ( $\mathrm{r} \sim 0.7)$ [164]. A small but consistent bias towards under-estimation of absence data by selfreport is accounted for using a correction factor. Presenteeism was calculated for each worker in terms of hours lost per month, and as an annualised estimate, by combining hours worked with job performance rating. Validation studies show that HPQ self-reports of presenteeism correlate well with independent assessments such as work audits, supervisor ratings and peer ratings across a broad range of industries and occupations [164]. The common metric allows not only a consolidated total work productivity loss measure, but also facilitates cost modelling [165] based on salary conversion methods using a human capital approach, which expresses productivity loss as the product of lost work time and salary [166]. The questionnaire was completed at the time of the overnight sleep study and then online following a text message screening question prompt every 3 months for the following 12 months.

The HPQ also includes self-reported status for 28 health conditions covering 9 broad domains [122]. This study used a similar, self-reported list of health conditions to be consistent with those used in previous Raine follow-ups [167], which has good overlap with the HPQ for common conditions but also includes conditions potentially important for work productivity loss in this agegroup but not covered by the HPQ, such as menstrual disorders. Self-report of conditions on such checklists has a high concordance with medical records [168].

\section{Sleep}

Polysomnography Standard, overnight monitored polysomnography was performed in home-like bedrooms at the University of Western Australia's Centre for Sleep Science. Measurements included electroencephalogram, electrooculograms, submental electromyogram, oronasal airflow, chest wall motion, and arterial oxygen saturation. All studies were monitored by a Sleep Scientist. Scoring for sleep stages, respiratory events and arousals were performed according to current American Academy of Sleep Medicine criteria [169].

Sleep questionnaires The following sleep-related questionnaires were also administered: Pittsburgh Sleep Quality Index: a self-administered questionnaire that measures sleep quality and sleep disturbance retrospectively over a one month period; the Berlin questionnaire: a selfadministered questionnaire that identifies individuals at risk 
for the sleep apnea syndrome; the Epworth Sleepiness questionnaire: a self-administered questionnaire regarding the levels of daytime sleepiness in various situations; and, the short Functional Outcomes of Sleep Questionnaire: a selfadministered questionnaire designed to assess the impact of excessive sleepiness on multiple activities of everyday living (activity, vigilance, relationships, productivity, social outcome).

Sleep accelerometry Wrist and hip accelerometry was undertaken for one week (see physical activity section for details).

Sleep diary Sleep diary was given to each participant at the overnight sleep study in order to document sleep quality and sleep hours for a week in their normal lives (see physical activity section for details).

\section{Additional variables}

Additional variables were collected by questionnaire and physical assessment to continue collation of longitudinal measures regularly collected from the cohort, and other variables of particular interest to investigators. These are summarised as follows:

Sociodemographic variables collected by questionnaire included family structure, residential situation, education, occupation, income, and ancestry. Health variables collected by questionnaire included diagnosed disorders, medical history, medication use, and health services utilised. Lifestyle variables collected by questionnaire included sunlight exposure, diet, smoking, alcohol and other drug use. Quality of life was assessed using the SF12. [170] Psychological variables included depression, anxiety and stress, assessed by the Depression, Anxiety and Stress Scale-short form (DASS-21) [171].

Physical assessments using established, standard methods included height (stadiometer, unshod), weight (electronic scale, light clothing), chest, waist and hip circumference (flexible tape), subscapular, triceps, supraspinale/suprailiac and abdominal skinfolds (Holtain calipers), blood pressure and resting heart rate (Dinamap). Additional anthropometric measures related to sleep issues included neck circumference, observations for Mallampati score and pharyngeal grade, and intra-oral and three dimensional facial photographs. Mole counts on one arm and skin wrinkling impression on dorsum of hand were also taken. Evening and morning urine samples were taken for later processing. Cognitive function was objectively assessed using subtests of the CogState (CogState Ltd, Melbourne, Australia), a computerized test battery developed in Australia, measuring speed of processing, sustained attention (vigilance), working memory and executive function, and and visual learning and recall. For each subtest, hit rates and mean reaction times provide sensitive indices of performance. The assessment is suitable for participants aged 6 to 106 , and has been used to assess the cognitive consequences of a number of disorders [172].

\section{Procedures}

The procedures followed standard practices used with this cohort since inception. At around the time of their 22nd birthday (2012-2014) each participant was contacted by telephone and had the details of this follow-up explained. Those wishing to participate were mailed questionnaires, participant information and a consent form prior to their scheduled appointment for a physical assessment session and overnight sleep study. The questionnaire took approximately $2 \mathrm{~h}$ to complete. The physical assessments took approximately $3 \mathrm{~h}$ to complete plus an additional one and a half hours for sleep study set up.

All data were entered into the Raine Study database and quality controlled using standard procedures. These new data were added to the existing database of over 85,000 phenotypic variables, 31 million genetic variables, and the 170,000 biological samples curated (Table 1).

\section{Analysis}

Aim 1

Descriptive statistics with precision estimates will be used to report the prevalence of each critical health issue and behaviour using cross-sectional 22 year data.

\section{Aim 2}

Phenotypes, detailed profiles and patterns of each health issue, at 22 year will be described. Comparisons between groups with and without each health issue (e.g. atopic vs non-atopic asthma, active vs inactive) will be conducted using general linear models.

\section{Aim 3}

Early life predictors will be assessed using variables that have been measured repeatedly over the prior 20 years of the cohort to establish developmental trajectories for

Table 1 Longitudinal data available on Raine Study participants

\begin{tabular}{|c|c|c|c|c|c|c|c|c|c|c|c|c|}
\hline \multirow[b]{2}{*}{ variable } & \multicolumn{12}{|c|}{ Age (years) } \\
\hline & 18 weeks & birth & 1 & 2 & 3 & 5 & 8 & 10 & 14 & 17 & 20 & 22 \\
\hline parental & + & + & + & + & + & + & + & + & + & + & & \\
\hline genetic & & & & & & & & & + & + & & \\
\hline physical & + & + & + & + & + & + & + & + & + & + & + & + \\
\hline mental & & + & + & + & + & + & + & + & + & + & + & + \\
\hline behavioural & & & + & + & + & + & + & + & + & + & + & + \\
\hline environmental & + & + & + & + & + & + & + & + & + & + & + & + \\
\hline
\end{tabular}


each phenotype. Specific risk factor variables were selected based on previous literature, exploratory correlations, and exploratory factor analysis. A generalised linear model framework (multivariable logistic regression) will explore the strength of association of these factors with the presence of each phenotype both univariately and collectively. Where repeated measures of a predictor are available (e.g. Body Mass Index), latent growth curve analysis will be used to characterise risk factor trajectory data for use in the logistic regression model [14]. For binary outcomes, logistic regression, with population-averaged approaches or random effects, will be used [173].

More detailed secondary analyses will be conducted specific to each health issue and non-parametric models used when necessary.

\section{Discussion}

The 22 year follow-up of the Raine Study cohort provides unprecedented data on the prevalence, clinical picture (phenotype), risk factors and inter-relationships for multiple health conditions and behaviours among young adults.

\section{Prevalence}

Disease prevalence data are vital to enable adequate planning by health authorities and to facilitate appropriate allocation of healthcare resources. The focus on young adults is also appropriate given the lack of data in this age-group across the health conditions, and the potential positive impact of early identification on public health and clinical measures to improve quality of life and alleviate risk for long-term health outcomes. For example, international evidence shows that young adulthood is a critical time for development of lifelong behaviours but also for increasing inactivity and sedentary behaviour. Therefore, there is considerable potential for the findings from this study favourably to impact on long-term musculoskeletal, respiratory, cardiovascular, metabolic and other health outcomes by informing public health planning and the development of early preventative strategies.

\section{Phenotype}

The study had adequate power to define the clinical features and phenotype of health conditions, behaviours and consequences in young adults. Such information can be used to educate primary care physicians in early case identification. Detailed measurement at 22 years of age also provides an excellent baseline for subsequent research not only to track these behaviours into middle age and beyond, but also to test hypotheses about the contribution that early symptoms and behaviours make to the complex pathways to many chronic diseases in adulthood.

\section{Risk factors}

The study can identify unique and cross-cutting risk factors for multiple health conditions. For example, obesity at an early age may contribute to OSA, asthma, increased spinal pain and increased sedentary time. The Raine cohort has prospectively collected detailed longitudinal data and provides an ideal platform to evaluate the role played by developmental and environmental factors. Findings from this study will have important public health planning implications, potentially leading to the development of early preventative strategies including early identification of high-risk individuals and, ultimately, targeted treatment, which may prevent disease onset or modify disease course. Young adults are also frequently becoming parents, thus assisting improvements in their health and related behaviours is likely to have benefits not only for their own health but also for the health of their offspring.

\section{Inter-relationships}

These five areas of focus for the 22 year follow-up are likely to be related. For example, physical activity and reduced sedentary time are associated with spinal pain [174], asthma [175] and sleep [176]. Further, sleep disorders such as obstructive sleep apnea (OSA) are likely to be influenced by physical activity. In middle aged adults there is an association between the severity of OSA and reported hours exercised per week, independent of traditional covariates, including BMI [177], suggesting that physical activity may be an additional, potentially modifiable, risk factor. These relationships may also be bidirectional. For example, while high levels of physical activity may lead to back pain, disabling LBP is also associated with activity avoidance and physical deconditioning [178]. In addition to direct relationships, there are likely to be several common, early life and young adulthood risk factors. For example, obesity is a risk factor that may influence pain, asthma, sleep disorders and limit physical activity and work productivity via a number of different mechanisms [179]. All of these health conditions and behaviours may contribute to work productivity.

\section{Conclusion}

A major focus of health and medical research today is on developing a better understanding of the underlying mechanisms, and addressing the rising prevalence, of lifestyle-related chronic diseases whilst encouraging healthy lifestyles. The Raine Study is uniquely placed to contribute to this via its breadth and depth of multidisciplinary information. There are few community cohorts that have been followed from before birth into adulthood in such rich detail. This continuing examination of the Raine cohort in early adulthood and beyond will provide critical information on the development of multiple, chronic health conditions and their impact on society. 


\section{Abbreviations}

BMI: Body Mass Index; FEF: forced expiratory flow; FEV: forced expiratory volume; FVC: forced vital capacity; HPQ: Health and Productivity Questionnaire; OSA: Obstructive Sleep Apnea; PSG: polysomnography; Zrs: mechanical impedance of the respiratory system.

\section{Competing interests}

Graham Hall has received research support from Pharmaxis Ltd. Nigel McArdle has received research support from ResMed Ltd and an Honorarium for participating at a ResMed Ltd breakfast symposium. Peter Eastwood has received research support from ResMed Ltd and Apnex Medical Inc. The remaining authors have no competing interests.

\section{Authors' contributions}

$L S, P E$, and GH designed the study and lead the grant applications to fund the study. NMcA contributed to the sleep grant application and protocol development, EW contributed to the asthma protocol development and JM contributed to the integration of the various protocols. EH and LS drafted the manuscript based on grant applications written by all investigators. All authors read, revised and approved the final manuscript.

\section{Acknowledgements}

We would like to acknowledge the Raine Study participants for their ongoing participation in the study and the Raine Study Team for study co-ordination and data collection.

The 22 year Raine Study follow-up was funded by National Health and Medical Research Council of Australia (NHMRC) project grants 1027449, 1044840 and 1021858. Funding was also generously provided by Safe Work Australia. LS, GH, PE supported by NHMRC research fellowships (1019980, 1025550, 1042341). We would like to acknowledge the University of Western Australia (UWA), Curtin University, the Raine Medical Research Foundation, the UWA Faculty of Medicine, Dentistry and Health Sciences, the Telethon Kids Institute, the Women's and Infant's Research Foundation (KEMH) and Edith Cowan University for providing funding for the Core Management of the Raine Study. The Raine Study 22 year follow-up investigator group included: For musculoskeletal and work productivity - Anne Smith, Darren Beales, Peter O'Sullivan, Steven Linton, Glenn Pransky, Su Mon Kyaw-Myint, Jenny Job, Rachel Moorin.

For asthma - Pat Holt, Elysia Hollams, Zoltan Hantos, Peter Sly, Nick de Klerk and Alan James.

For sleep - David Hillman, Anne Smith, Rae Chi Huang, Craig Pennell, Elizabeth Davis, Romola Bucks, Nick de Klerk.

For sedentary behaviour and physical activity - Genevieve Healy, Elizabeth Winkler, Rebecca Abbott, Gita Mishra, Mark Tremblay.

And for Raine Study follow-up overall management -Dianne Wood and Angela Jacques.

\section{Author details}

'School of Physiotherapy and Exercise Science, Curtin University, GPO Box U1987, Perth, WA 6845, Australia. ${ }^{2}$ Telethon Kids Institute, University of Western Australia, Crawley, Australia. ${ }^{3}$ The University of Western Australia, Perth, WA, Australia. ${ }^{4}$ Curtin University, Perth, WA, Australia. ${ }^{5}$ Royal Perth Hospital, Perth, WA, Australia.

Received: 28 April 2015 Accepted: 16 June 2015

\section{Published online: 14 July 2015}

\section{References}

1. Newnham JP, Evans SF, Michael CA, Stanley FJ, Landau LI. Effects of frequent ultrasound during pregnancy: a randomised controlled trial. Lancet. 1993;342(8876):887-91.

2. Williams LA, Evans SF, Newnham JP. Prospective cohort study of factors influencing the relative weights of the placenta and the newborn infant BMJ. 1997;314(7098):1864-8.

3. Elder Jr GH, Johnson MK, Crosnoe R. The emergence and development of life course theory. New York: Springer; 2003.

4. Power C, Kuh D, Morton S. From developmental origins of adult disease to life course research on adult disease and aging: insights from birth cohort studies. Annu Rev Public Health. 2013;34:7-28.

5. Bonnie RJ, Stroud C, Breiner H. Investing in the Health and Well-Being of Young Adults. Washington, D.C.: National Academies Press; 2015.
6. Huizinga M, Dolan CV, van der Molen MW. Age-related change in executive function: developmental trends and a latent variable analysis. Neuropsychologia. 2006;44(11):2017-36.

7. Tai A, Tran H, Roberts M, Clarke N, Wilson J, Robertson CF. The association between childhood asthma and adult chronic obstructive pulmonary disease. Thorax. 2014;69(9):805-10.

8. Vos T, Flaxman AD, Naghavi M, Lozano R, Michaud C, Ezzati M, et al. Years lived with disability (YLDs) for 1160 sequelae of 289 diseases and injuries 1990-2010: a systematic analysis for the Global Burden of Disease Study 2010. Lancet. 2012;380(9859):2163-96.

9. Hoy D, Protani M, De R, Buchbinder R. The epidemiology of neck pain. Best Pract Res Clinical Rheumatol. 2010;24(6):783-92.

10. Walker BF, Muller R, Grant WD. Low back pain in Australian adults: the economic burden. Asia Pac J Public Health. 2003;15(2):79-87.

11. Watson KD, Papageorgiou AC, Jones GT, Taylor S, Symmons DP, Silman AJ, et al. Low back pain in schoolchildren: occurrence and characteristics. Pain. 2002;97(1-2):87-92.

12. Hestbaek L, Leboeuf-Yde C, Kyvik KO. Is comorbidity in adolescence a predictor for adult low back pain? A prospective study of a young population. BMC Musculoskelet Disord. 2006;7.

13. Pellise F, Balague F, Rajmil L, Cedraschi C, Aguirre M, Fontecha CG, et al. Prevalence of low back pain and its effect on health-related quality of life in adolescents. Arch Pediatr Adolesc Med. 2009;163(1):65-71.

14. Smith AJ, O'Sullivan PB, Beales DJ, de Klerk N, Straker LM. Trajectories of childhood body mass index are associated with adolescent sagittal standing posture. Int J Pediatr Obes. 2010;6:e97-196.

15. Kopec JA, Sayre EC. Stressful experiences in childhood and chronic back pain in the general population. Clin J Pain. 2005;21(6):478-83.

16. Gatchel RJ, Peng YB, Peters ML, Fuchs PN, Turk DC. The biopsychosocial approach to chronic pain: scientific advances and future directions. Psychol Bull. 2007;133(4):581-624.

17. von Baeyer CL, Champion GD. Commentary: multiple pains as functional pain syndromes. J Pediatr Psychol. 2011;36:433-7.

18. Andersson GB. Epidemiological features of chronic low-back pain. Lancet. 1999;354(9178):581-5.

19. Walker BF, Muller R, Grant WD. Low back pain in Australian adults: prevalence and associated disability. J Manipulative Physiol Ther. 2004;27(4):238-44.

20. Mitchell T, O'Sullivan PB, Burnett AF, Straker L, Rudd C. Low back pain characteristics from undergraduate student to working nurse in Australia: A cross-sectional survey. Int J Nurs Stud. 2008;45(11):1636-44.

21. Burton AK, Balague F, Cardon G, Eriksen HR, Henrotin Y, Lahad A, et al. Chapter 2. European guidelines for prevention in low back pain: November 2004. Eur Spine J. 2006;15 Suppl 2:S136-68.

22. Artus M, van der Windt DA, Jordan KP, Hay EM. Low back pain symptoms show a similar pattern of improvement following a wide range of primary care treatments: a systematic review of randomized clinical trials. Rheumatology (Oxford). 2010;49(12):2346-56.

23. Foster NE, Dziedzic KS, van der Windt DA, Fritz JM, Hay EM. Research priorities for non-pharmacological therapies for common musculoskeletal problems: nationally and internationally agreed recommendations. BMC Musculoskelet Disord. 2009;10:3.

24. Cruz AA, Bousquet J, Khaltaev N. Global surveillance, prevention and control of chronic respiratory diseases: a comprehensive approach. Switzerland: World Health Organization; 2007.

25. World Health Organization. Asthma. 2015. http://www.who.int/respiratory/ asthma/en/. Accessed April 22015.

26. Global Initiative for Asthma. Global Strategy for Asthm Management and Prevention 2014. 2014. www.ginasthma.org. Accessed April 22015.

27. Stern DA, Morgan WJ, Wright AL, Guerra S, Martinez FD. Poor airway function in early infancy and lung function by age 22 years: a non-selective longitudinal cohort study. Lancet. 2007;370(9589):758-64.

28. Sly PD. The early origins of asthma: who is really at risk? Curr Opin Allergy Clin Immunol. 2011;11(1):24-8.

29. Postma DS, Bush A, van den Berge M. Risk factors and early origins of chronic obstructive pulmonary disease. Lancet. 2015;385(9971):899-909.

30. Zosky GR, Hart PH, Whitehouse AJ, Kusel MM, Ang W, Foong RE, et al. Vitamin $D$ deficiency at 16 to 20 weeks' gestation is associated with impaired lung function and asthma at 6 years of age. Ann Am Thorac Soc. 2014;11(4):571-7.

31. Pike KC, Crozier SR, Lucas JS, Inskip HM, Robinson S, Roberts G, et al. Patterns of fetal and infant growth are related to atopy and wheezing disorders at age 3 years. Thorax. 2010;65(12):1099-106. 
32. Collins RA, Parsons F, Deverell M, Hollams EM, Holt PG, Sly PD. Risk factors for bronchial hyperresponsiveness in teenagers differ with sex and atopic status. J Allergy Clin Immunol. 2011;128(2):301-7.e1.

33. Oddy WH, de Klerk NH, Sly PD, Holt PG. The effects of respiratory infections, atopy, and breastfeeding on childhood asthma. Eur Respir J. 2002;19(5):899-905.

34. Xuan W, Peat JK, Toelle BG, Marks GB, Berry G, Woolcock AJ. Lung function growth and its relation to airway hyperresponsiveness and recent wheeze. Results from a longitudinal population study. Am J Respir Crit Care Med. 2000;161(6):1820-4.

35. James AL, Palmer $\sqcup$, Kicic E, Maxwell PS, Lagan SE, Ryan GF, et al. Decline in lung function in the Busselton Health Study: the effects of asthma and cigarette smoking. Am J Respir Crit Care Med. 2005;171(2):109-14.

36. Turner SW, Palmer $\amalg$, Rye PJ, Gibson NA, Judge PK, Cox M, et al. The relationship between infant airway function, childhood airway responsiveness, and asthma. Am J Respir Crit Care Med. 2004;169(8):921-7.

37. Sly PD, Boner AL, Bjorksten B, Bush A, Custovic A, Eigenmann PA, et al. Early identification of atopy in the prediction of persistent asthma in children. Lancet. 2008;372(9643):1100-6.

38. Hollams EM, Deverell M, Serralha M, Suriyaarachchi D, Parsons F, Zhang G, et al. Elucidation of asthma phenotypes in atopic teenagers through parallel immunophenotypic and clinical profiling. J Allergy Clin Immunol. 2009;124(3):463-70, 470.e1-16

39. Custovic A, Soderstrom L, Ahlstedt S, Sly PD, Simpson A, Holt PG. Allergenspecific lgG antibody levels modify the relationship between allergenspecific IgE and wheezing in childhood. J Allergy Clin Immunol. 2011;127(6):1480-5.

40. Holt PG, Sly PD. Non-atopic intrinsic asthma and the 'family tree' of chronic respiratory disease syndromes. Clin Exp Allergy. 2009;39(6):807-11.

41. Bush A. COPD: a pediatric disease. COPD. 2008:5(1):53-67.

42. Phelan PD, Robertson CF, Olinsky A. The Melbourne Asthma Study: 1964-1999. J Allergy Clin Immunol. 2002:109(2):189-94.

43. Ali NJ, Pitson DJ, Stradling JR. Snoring, sleep disturbance, and behaviour in 4-5 year olds. Arch Dis Child. 1993;68(3):360-6.

44. Anuntaseree W, Rookkapan K, Kuasirikul S, Thongsuksai P. Snoring and obstructive sleep apnea in Thai school-age children: prevalence and predisposing factors. Pediatr Pulmonol. 2001;32(3):222-7.

45. Gislason T, Benediktsdottir B. Snoring, apneic episodes, and nocturnal hypoxemia among children 6 months to 6 years old. An epidemiologic study of lower limit of prevalence. Chest. 1995;107(4):963-6.

46. Young T, Palta M, Dempsey J, Skatrud J, Weber S, Badr S. The occurrence of sleep-disordered breathing among middle-aged adults. N Engl J Med. 1993;328(17):1230-5.

47. Bearpark H, Elliott L, Grunstein R, Cullen S, Schneider H, Althaus W, et al. Snoring and sleep apnea. A population study in Australian men. Am J Respir Crit Care Med. 1995;151(5):1459-65.

48. Ip MS, Lam B, Lauder IJ, Tsang KW, Chung KF, Mok YW, et al. A community study of sleep-disordered breathing in middle-aged Chinese men in Hong Kong. Chest. 2001;119(1):62-9.

49. Baldwin CM, Griffith KA, Nieto FJ, O'Connor GT, Walsleben JA, Redline S. The association of sleep-disordered breathing and sleep symptoms with quality of life in the Sleep Heart Health Study. Sleep. 2001;24(1):96-105.

50. Finn L, Young T, Palta M, Fryback DG. Sleep-disordered breathing and selfreported general health status in the Wisconsin Sleep Cohort Study. Sleep. 1998;21(7):701-6.

51. Tregear S, Reston J, Schoelles K, Phillips B. Obstructive sleep apnea and risk of motor vehicle crash: systematic review and meta-analysis. J Clin Sleep Med. 2009;5(6):573-81.

52. Peppard PE, Young T, Palta M, Skatrud J. Prospective study of the association between sleep-disordered breathing and hypertension. N Engl J Med. 2000;342(19):1378-84.

53. Marin JM, Carrizo SJ, Vicente E, Agusti AG. Long-term cardiovascular outcomes in men with obstructive sleep apnoea-hypopnoea with or without treatment with continuous positive airway pressure: an observational study. Lancet. 2005;365(9464):1046-53.

54. Punjabi NM, Caffo BS, Goodwin JL, Gottlieb DJ, Newman AB, O'Connor GT, et al. Sleep-disordered breathing and mortality: a prospective cohort study. PLoS Med. 2009;6(8):e1000132.

55. Rosen CL, Larkin EK, Kirchner HL, Emancipator JL, Bivins SF, Surovec SA, et al. Prevalence and risk factors for sleep-disordered breathing in 8- to 11-year-old children: association with race and prematurity. J Pediatr. 2003;142(4):383-9.
56. Kohler MJ, Thormaehlen S, Kennedy JD, Pamula Y, van den Heuvel CJ, Lushington $\mathrm{K}$, et al. Differences in the association between obesity and obstructive sleep apnea among children and adolescents. J Clin Sleep Med. 2009;5(6):506-11.

57. Barker DJ, Osmond C, Forsen TJ, Kajantie E, Eriksson JG. Trajectories of growth among children who have coronary events as adults. N Engl J Med. 2005;353(17):1802-9.

58. Stettler N, Stallings VA, Troxel AB, Zhao J, Schinnar R, Nelson SE, et al. Weight gain in the first week of life and overweight in adulthood: a cohort study of European American subjects fed infant formula. Circulation. 2005;111(15):1897-903.

59. Lofstrand-Tidestrom B, Thilander B, Ahlqvist-Rastad J, Jakobsson O, Hultcrantz E. Breathing obstruction in relation to craniofacial and dental arch morphology in 4-year-old children. Eur J Orthod. 1999;21(4):323-32.

60. Redline S, Schluchter MD, Larkin EK, Tishler PV. Predictors of longitudinal change in sleep-disordered breathing in a nonclinic population. Sleep. 2003;26(6):703-9.

61. Bixler EO, Vgontzas AN, Ten Have T, Tyson K, Kales A. Effects of age on sleep apnea in men: I. Prevalence and severity. Am J Respir Crit Care Med. 1998;157(1):144-8.

62. Duran J, Esnaola S, Rubio R, Iztueta A. Obstructive sleep apnea-hypopnea and related clinical features in a population-based sample of subjects aged 30 to 70 yr. Am J Respir Crit Care Med. 2001;163(3 Pt 1):685-9.

63. Castronovo V, Zucconi M, Nosetti L, Marazzini C, Hensley M, Veglia F, et al. Prevalence of habitual snoring and sleep-disordered breathing in preschool-aged children in an Italian community. J Pediatr. 2003:142(4):377-82.

64. Goodwin JL, Kaemingk KL, Fregosi RF, Rosen GM, Morgan WJ, Sherrill DL, et al. Clinical outcomes associated with sleep-disordered breathing in Caucasian and Hispanic children-the Tucson Children's Assessment of Sleep Apnea study (TuCASA). Sleep. 2003;26(5):587-91.

65. Sogut A, Altin R, Uzun L, Ugur MB, Tomac N, Acun C, et al. Prevalence of obstructive sleep apnea syndrome and associated symptoms in 3-11-yearold Turkish children. Pediatr Pulmonol. 2005;39(3):251-6.

66. Brunetti L, Rana S, Lospalluti ML, Pietrafesa A, Francavilla R, Fanelli M, et al. Prevalence of obstructive sleep apnea syndrome in a cohort of 1,207 children of southern Italy. Chest. 2001;120(6):1930-5.

67. Urschitz MS, Brockmann PE, Schlaud M, Poets CF. Population prevalence of obstructive sleep apnoea in a community of German third graders. Eur Respir J. 2010;36(3):556-68.

68. Sanchez-Armengol A, Fuentes-Pradera MA, Capote-Gil F, Garcia-Diaz E, Cano-Gomez S, Carmona-Bernal C, et al. Sleep-related breathing disorders in adolescents aged 12 to 16 years : clinical and polygraphic findings. Chest. 2001;119(5):1393-400.

69. Kaditis AG, Finder J, Alexopoulos El, Starantzis K, Tanou K, Gampeta S, et al. Sleep-disordered breathing in 3,680 Greek children. Pediatr Pulmonol. 2004;37(6):499-509.

70. Redline S, Tishler PV, Schluchter M, Aylor J, Clark K, Graham G. Risk factors for sleep-disordered breathing in children. Associations with obesity, race, and respiratory problems. Am J Respir Crit Care Med. 1999;159(5 Pt 1):1527-32.

71. Ancoli-Israel S, Kripke DF, Klauber MR, Mason WJ, Fell R, Kaplan O. Sleepdisordered breathing in community-dwelling elderly. Sleep. 1991;14(6):486-95.

72. Hoch CC, Reynolds 3rd CF, Monk TH, Buysse DJ, Yeager AL, Houck PR, et al. Comparison of sleep-disordered breathing among healthy elderly in the seventh, eighth, and ninth decades of life. Sleep. 1990;13(6):502-11.

73. Young T, Shahar E, Nieto FJ, Redline S, Newman AB, Gottlieb DJ, et al. Predictors of sleep-disordered breathing in community-dwelling adults: the Sleep Heart Health Study. Arch Intern Med. 2002;162(8):893-900.

74. Kim J, In K, You S, Kang K, Shim J, Lee S, et al. Prevalence of sleepdisordered breathing in middle-aged Korean men and women. Am J Respir Crit Care Med. 2004;170(10):1108-13.

75. Kripke DF, Ancoli-Israel S, Klauber MR, Wingard DL, Mason WJ, Mullaney DJ. Prevalence of sleep-disordered breathing in ages 40-64 years: a population-based survey. Sleep. 1997;20(1):65-76.

76. Stradling JR, Crosby JH. Predictors and prevalence of obstructive sleep apnoea and snoring in 1001 middle aged men. Thorax. 1991;46(2):85-90.

77. Mihaere KM, Harris R, Gander PH, Reid PM, Purdie G, Robson B, et al. Obstructive sleep apnea in New Zealand adults: prevalence and risk factors among Maori and non-Maori. Sleep. 2009;32(7):949-56. 
78. Sharma SK, Kumpawat S, Banga A, Goel A. Prevalence and risk factors of obstructive sleep apnea syndrome in a population of Delhi, India. Chest. 2006;130(1):149-56.

79. Gislason T, Almqvist M, Eriksson G, Taube A, Boman G. Prevalence of sleep apnea syndrome among Swedish men-an epidemiological study. J Clin Epidemiol. 1988;41(6):571-6.

80. Bixler EO, Vgontzas AN, Lin HM, Ten Have T, Rein J, Vela-Bueno A, et al. Prevalence of sleep-disordered breathing in women: effects of gender. Am J Respir Crit Care Med. 2001;163(3 Pt 1):608-13.

81. Young T, Evans L, Finn L, Palta M. Estimation of the clinically diagnosed proportion of sleep apnea syndrome in middle-aged men and women. Sleep. 1997;20(9):705-6.

82. Begg S, Vos T, Barker B, Stevenson C, Stanley L, Lopez A. Burden of disease and injury in Australia, 2003. Australian Institute of Health and Welfare: Canberra; 2007.

83. Tremblay MS, Colley RC, Saunders TJ, Healy GN, Owen N. Physiological and health implications of a sedentary lifestyle. Appl Physiol Nutr Metab. 2010;35(6):725-40.

84. Straker L, Mathiassen SE. Increased physical work loads in modern work-a necessity for better health and performance? Ergonomics. 2009;52(10):1215-25.

85. Troiano RP, Berrigan D, Dodd KW, Masse LC, Tilert T, McDowell M. Physical activity in the United States measured by accelerometer. Med Sci Sports Exerc. 2008;40(1):181-8

86. Colley RC, Garriguet D, Janssen I, Craig CL, Clarke J, Tremblay MS. Physical activity of Canadian adults: accelerometer results from the 2007 to 2009 Canadian Health Measures Survey. Health Rep. 2011;22(1):7-14.

87. World Health Organization. Global Recommendations on Physical Activity for Health. Geneva: World Health Organization; 2010.

88. MedibankPrivate. The cost of physical inactivity. Australia; 2008.

89. Katzmarzyk PT, Church TS, Craig CL, Bouchard C. Sitting time and mortality from all causes, cardiovascular disease, and cancer. Med Sci Sports Exerc. 2009:41(5):998-1005.

90. Salmon J, Bauman A, Crawford D, Timperio A, Owen N. The association between television viewing and overweight among Australian adults participating in varying levels of leisure-time physical activity. Int J Obes Relat Metab Disord. 2000;24(5):600-6.

91. Healy GN, Dunstan DW, Salmon J, Cerin E, Shaw JE, Zimmet PZ, et al. Breaks in sedentary time: beneficial associations with metabolic risk. Diabetes Care. 2008;31(4):661-6.

92. Hancox RJ, Milne BJ, Poulton R. Association between child and adolescent television viewing and adult health: a longitudinal birth cohort study. Lancet. 2004;364(9430):257-62.

93. Healy GN, Wijndaele K, Dunstan DW, Shaw JE, Salmon J, Zimmet PZ, et al. Objectively measured sedentary time, physical activity, and metabolic risk: the Australian Diabetes, Obesity and Lifestyle Study (AusDiab). Diabetes Care. 2008:31(2):369-71.

94. Tremblay MS, LeBlanc AG, Kho ME, Saunders TJ, Larouche R, Colley RC, et al. Systematic review of sedentary behaviour and health indicators in school-aged children and youth. Int J Behav Nutr Phys Act. 2011;8:98.

95. Tremblay MS, LeBlanc AG, Carson V, Choquette L, Connor Gorber S, Dillman C, et al. Canadian Sedentary Behaviour Guidelines for the Early Years (aged 0-4 years). Appl Physiol Nutr Metab. 2012;37:370-91.

96. Healy GN, Matthews CE, Dunstan DW, Winkler EA, Owen N. Sedentary time and cardio-metabolic biomarkers in US adults: NHANES 2003-06. Eur Heart J. 2011;32(5):590-7.

97. Healy GN, Dunstan DW, Salmon J, Cerin E, Shaw JE, Zimmet PZ, et al. Objectively measured light-intensity physical activity is independently associated with 2-h plasma glucose. Diabetes Care. 2007;30(6):1384-9.

98. Matthews CE, Chen KY, Freedson PS, Buchowski MS, Beech BM, Pate RR, et al. Amount of time spent in sedentary behaviors in the United States, 2003-2004. Am J Epidemiol. 2008;167(7):875-81.

99. Van Dyck D, Cardon G, Deforche B, Owen N, Sallis JF, De Bourdeaudhuij I. Neighborhood walkability and sedentary time in Belgian adults. Am J Prev Med. 2010;39(1):25-32.

100. Uijtdewilligen L, Nauta J, Singh AS, van Mechelen W, Twisk JW, van der Horst K, et al. Determinants of physical activity and sedentary behaviour in young people: a review and quality synthesis of prospective studies. $\mathrm{Br}$ J Sports Med. 2011:45(11):896-905.

101. Owen N, Sugiyama T, Eakin EE, Gardiner PA, Tremblay MS, Sallis JF. Adults' sedentary behavior determinants and interventions. Am J Prev Med. 2011;41(2):189-96.
102. McLeroy KR, Bibeau D, Steckler A, Glanz K. An ecological perspective on health promotion programs. Health Educ Q. 1988;15(4):351-77.

103. Ball K, Cleland VJ, Timperio AF, Salmon J, Crawford DA. Socioeconomic position and children's physical activity and sedentary behaviors: longitudinal findings from the CLAN study. J Phys Act Health. 2009;6(3):289-98.

104. Karwowski W. Ergonomics and human factors: the paradigms for science, engineering, design, technology and management of human-compatible systems. Ergonomics. 2005;48(5):436-63.

105. Schultz IZ, Stowell AW, Feuerstein M, Gatchel RJ. Models of return to work for musculoskeletal disorders. J Occup Rehabil. 2007;17(2):327-52.

106. Mishra GD, Cooper R, Kuh D. A life course approach to reproductive health: theory and methods. Maturitas. 2010;65(2):92-7.

107. Organisation for Economic Co-operation and Development. OECD Compendium of Productivity Indicators 2012. OECD; 2012. www.oecd.org.

108. House of Representatives, House Standing Committee on Economics. Inquiry into raising the productivity growth rate in the Australian economy. Australian Government; 2010. www.aph.gov.au.

109. Productivity Commission. Australia's Productivity Performance: Submission to the House of Representatives Standing Committee on Economics. Australian Government; 2009. www.pc.gov.au/_data/assets/pdf_file/ .../productivity-growth.pdf.

110. Taylor C, Bradley C, Dobbs R, Thompson F, Clifton D. Beyond the boom: Australia's productivity imperative: The McKinsey Global Institute. 2012.

111. Skill Australia. Australian Workforce Futures: A National Workforce Development Strategy. Australian Government; 2010. http://www.awpa.gov.au.

112. Australian Bureau of Statistics. Australian Social Trends: Retirement and retirement intentions (4102.0). Australian Bureau of Statistics; 2009. http://www.abs.gov.au/.

113. Australian Bureau of Statistics. Labour Force, Australia, Detailed - Electronic Delivery, Dec 2012 (6291.0.55.001). Australian Bureau of Statistics; 2012 http://www.abs.gov.au/.

114. Weil, David N. Accounting for the effect of health on economic growth. Q J Econ. 2007;122:1265-1306

115. Medibank Private. Sick at Work: The cost of presenteeism to your business and the economy. Medibank Private; 2011. http://www.medibank.com.au.

116. Bloom DE, Canning D. Health and Economic Growth: Reconciling the Micro and Macro Evidence: Stanford Institute on International Studies. 2005.

117. Australian Workforce and Productivity Agency. Future Focus: Australia's skill and workforce development needs. Australian Workforce and Productivity Agency; 2012. http://www.awpa.gov.au.

118. Australian Institute of Health and Welfare. Australia's Health 2010. Canberra: ACT: Australian Institute of Health and Welfare; 2010. Contract No.: Cat. no. AUS 122.

119. Sleep Health Foundation. Re-awakening Australia: The economic cost of sleep disorders in Australia, 2010. Sleep Health Foundation; 2011. http://www.sleephealthfoundation.org.au.

120. Australian Institute of Health and Welfare. 2010 National Drug Strategy Household Survey report. Australian Institute of Health and Welfare; 2011. http://www.aihw.gov.au.

121. Bergstrom G, Bodin L, Bertilsson H, Jensen IB. Risk factors for new episodes of sick leave due to neck or back pain in a working population. A prospective study with an 18-month and a three-year follow-up. Occup Environ Med. 2007;64(4):279-87.

122. Holden L, Scuffham PA, Hilton MF, Ware RS, Vecchio N, Whiteford HA. Which health conditions impact on productivity in working Australians? J Occup Environ Med. 2011;53(3):253-7.

123. Salo P, Oksanen T, Sivertsen B, Hall M, Pentti J, Virtanen M, et al. Sleep disturbances as a predictor of cause-specific work disability and delayed return to work. Sleep. 2010;33(10):1323-31.

124. Johns G. Presenteeism in the workplace: a review and research agenda. J Organiz Behav. 2010;31:519-42.

125. Safe Work Australia. Compendium of Workers' Compensation Statistics Australia 2009-10. Safe Work Australia; 2012. http://www.safeworkaustralia.gov.au.

126. Safe Work Australia. The Cost of Work-Related Injury and IIIness for Australian Employers, Workers and the Community: 2008-09. Safe Work Australia; 2012. http://www.safeworkaustralia.gov.au.

127. Safe Work Australia. Work-related injuries in Australia: Who did and didn't receive workers' compensation in 2009-10. Safe Work Australia; 2011. http://www.safeworkaustralia.gov.au. 
128. Smith GS, Sorock GS, Wellman HM, Courtney TK, Pransky GS. Blurring the distinctions between on and off the job injuries: similarities and differences in circumstances. Inj Prev. 2006;12(4):236-41.

129. Dagenais S, Caro J, Haldeman S. A systematic review of low back pain cost of illness studies in the United States and internationally. Spine J. 2008;8(1):8-20.

130. Tsai SP, Bhojani FA, Wendt JK. Risk factors for illness absence due to musculoskeletal disorders in a 4-year prospective study of a petroleummanufacturing population. J Occup Environ Med. 2011;53(4):434-40.

131. Chen J, Millar WJ. Are recent cohorts healthier than their predecessors. Statistics Canada: Health Reports; 2000.

132. Case A, Fertig A, Paxson C. The lasting impact of childhood health and circumstance. J Health Econ. 2005;24(2):365-89.

133. Hill MS, Sandfort JR. Effects of childhood poverty on productivity later in life: implications for public policy. Children Youth Serv Rev. 1995;17(1/2):91-126.

134. Jeffries LJ, Milanese SF, Grimmer-Somers KA. Epidemiology of adolescent spinal pain: a systematic overview of the research literature. Spine. 2007;32(23):2630-7.

135. Patel V, Flisher AJ, Hetrick S, McGorry P. Mental health of young people: a global public-health challenge. Lancet. 2007;369(9569):1302-13.

136. Kuorinka I, Jonsson B, Kilbom A, Vinterberg H, Biering-Sorensen F, Andersson G, et al. Standardised Nordic questionnaires for the analysis of musculoskeletal symptoms. Appl Ergon. 1987;18(3):233-7.

137. Bjorksten MG, Boquist B, Talback M, Edling C. The validity of reported musculoskeletal problems.A study of questionnaire answers in relation to diagnosed disorders and perception of pain. Appl Ergon. 1999;30(4):325-30.

138. Dionne CE, Dunn KM, Croft PR, Nachemson AL, Buchbinder R, Walker BF, et al. A consensus approach toward the standardization of back pain definitions for use in prevalence studies. Spine. 2008:33(1):95-103.

139. Wedderkopp N, Leboeuf-Yde C, Andersen LB, Froberg K, Hansen HS. Back pain reporting pattern in a Danish population-based sample of children and adolescents. Spine. 2001;26(17):1879-83.

140. Jones MA, Hitchen PJ. The prevalence of low back pain in British schoolchildren. J Sports Sci. 2000;18(1):15-6.

141. Linton SJ, Hallden K. Can we screen for problematic back pain? A screening questionnaire for predicting outcome in acute and subacute back pain. Clin J Pain. 1998;14(3):209-15.

142. Biering-Sorensen F. Physical measurements as risk indicators for low-back trouble over a one-year period. Spine. 1984:9(2):106-19.

143. Salminen JJ, Maki P, Oksanen A, Pentti J. Spinal mobility and trunk muscle strength in 15-year-old schoolchildren with and without low-back pain. Spine. 1992;17(4):405-11.

144. Moreau CE, Green BN, Johnson CD, Moreau SR. Isometric back extension endurance tests: a review of the literature. J Manipulative Physiol Ther. 2001;24(2):110-22

145. Sterling M, Jull G, Kenardy J. Physical and psychological factors maintain long-term predictive capacity post-whiplash injury. Pain. 2006;122(1-2):102-8.

146. Asher MI, Keil U, Anderson HR, Beasley R, Crane J, Martinez F, et al. International Study of Asthma and Allergies in Childhood (ISAAC): rationale and methods. Eur Respir J. 1995;8(3):483-91.

147. Oddy WH. Breastfeeding and asthma in children: findings from a West Australian study. Breastfeed Rev. 2000;8(1):5-11

148. Miller MR, Hankinson J, Brusasco V, Burgos F, Casaburi R, Coates A, et al. Standardisation of spirometry. Eur Respir J. 2005;26(2):319-38.

149. Quanjer PH, Stanojevic S, Cole TJ, Baur X, Hall GL, Culver BH, et al. Multiethnic reference values for spirometry for the 3-95-yr age range: the global lung function 2012 equations. Eur Respir J. 2012;40(6):1324-43.

150. Hall GL, Thompson BR, Stanojevic S, Abramson MJ, Beasley R, Coates A, et al. The Global Lung Initiative 2012 reference values reflect contemporary Australasian spirometry. Respirology. 2012;17(7):1150-1.

151. Thamrin C, Finucane KE, Singh B, Hantos Z, Sly PD. Volume dependence of high-frequency respiratory mechanics in healthy adults. Ann Biomed Eng. 2008;36(1):162-70

152. Brannan JD, Porsbjerg C, Anderson SD. Inhaled mannitol as a test for bronchial hyper-responsiveness. Expert Rev Respir Med. 2009;3(5):457-68.

153. American Thoracic Society, European Respiratory Society. ATS/ERS recommendations for standardized procedures for the online and offline measurement of exhaled lower respiratory nitric oxide and nasal nitric oxide, 2005. Am J Respir Crit Care Med. 2005;171(8):912-30.

154. Leuppi JD, Salome CM, Jenkins CR, Koskela H, Brannan JD, Anderson SD, et al. Markers of airway inflammation and airway hyperresponsiveness in patients with well-controlled asthma. Eur Respir J. 2001;18(3):444-50.
155. Wood LG, Powell H, Gibson PG. Mannitol challenge for assessment of airway responsiveness, airway inflammation and inflammatory phenotype in asthma. Clin Exp Allergy. 2010;40(2):232-41.

156. Efthimiadis A, Spanevello A, Hamid Q, Kelly MM, Linden M, Louis R, et al. Methods of sputum processing for cell counts, immunocytochemistry and in situ hybridisation. Eur Respir J Suppl. 2002;37:19s-23.

157. Kelly MM, Keatings $V$, Leigh R, Peterson C, Shute J, Venge $P$, et al. Analysis of fluid-phase mediators. Eur Respir J Suppl. 2002;37:24s-39.

158. (ASCIA). Asociaa. Skin prick testing for the diagnosis of allergic disease. 2006.

159. Matthews CE, Hagstromer M, Pober DM, Bowles HR. Best practices for using physical activity monitors in population-based research. Med Sci Sports Exerc. 2012;44(1 Suppl 1):S68-76.

160. Sasaki JE, John D, Freedson PS. Validation and comparison of ActiGraph activity monitors. J Sci Med Sport. 2011;14(5):411-6.

161. Rideout VJ, Foehr UG, Roberts DF. Generation of M2 Media in the Lives of 8-18 Year Olds: A Kaiser Family Foundation Study. Ca.: Menlo Park; 2010.

162. Harris C, Straker L. Survey of physical ergonomics issues associated with school children's use of laptop computers. Int J Ind Ergon. 2000;26:337-46.

163. Kessler RC, Barber C, Beck A, Berglund P, Cleary PD, McKenas D, et al. The World Health Organization Health and Work Performance Questionnaire (HPQ). J Occup Environ Med. 2003;45(2):156-74.

164. Kessler RC, Ames M, Hymel PA, Loeppke R, McKenas DK, Richling DE, et al. Using the World Health Organization Health and Work Performance Questionnaire (HPQ) to evaluate the indirect workplace costs of illness. J Occup Environ Med. 2004;46(6 Suppl):S23-37.

165. Johns G. Attendance dynamics at work: the antecedents and correlates of presenteeism, absenteeism, and productivity loss. J Occup Health Psychol. 2011;16(4):483-500.

166. Mattke S, Balakrishnan A, Bergamo G, Newberry SJ. A review of methods to measure health-related productivity loss. Am J Manag Care. 2007;13(4):211-7.

167. Beales D, Smith A, O'Sullivan P, Straker L. Low back pain and comorbidity clusters at 17 years of age: a cross-sectional examination of health related quality of life and specific low back pain impacts. J Adolesc Health. 2012;50:509-16.

168. Kessler R, White LA, Birnbaum H, Qiu Y, Kidolezi Y, Mallett D, et al. Comparative and interactive effects of depression relative to other health problems on work performance in the workforce of a large employer. J Occup Environ Med. 2008;50(7):809-16.

169. Iber CA-IS, Chesson A, Quan S, for the American, Medicine. AoS. The AASM manual for the scoring of sleep and associated events: rules, terminology and technical specifications. 1st ed. Westchester, IL: American Academy of Sleep Medicine; 2007.

170. Ware JE, Kosinski M. SF-36 Physical \& Mental Health Summary Scales: A Manual for Users of Version 1. 2nd ed. Lincoln, Rl: QualityMetric; 2001.

171. Lovibond SH, Lovibond PF. Manual for the Depression Anxiety Stress Scales. Psychology Foundation: Sydney; 1995

172. Falleti MG, Maruff P, Collie A, Darby DG, McStephen M. Qualitative similarities in cognitive impairment associated with $24 \mathrm{~h}$ of sustained wakefulness and a blood alcohol concentration of 0.05 \%. J Sleep Res. 2003:12(4):265-74.

173. Neuhaus JM. Statistical methods for longitudinal and clustered designs with binary responses. Stat Methods Med Res. 1992;1(3):249-73.

174. Kwon BK, Roffey DM, Bishop PB, Dagenais S, Wai EK. Systematic review: occupational physical activity and low back pain. Occup Med (Lond) 2011;61(8):541-8.

175. Eijkemans M, Mommers M, Draaisma JM, Thijs C, Prins MH. Physical activity and asthma: a systematic review and meta-analysis. PLoS One. 2012;7(12):e50775.

176. Chennaoui M, Arnal PJ, Sauvet F, Leger D. Sleep and exercise: a reciprocal issue? Sleep Med Rev. 2015;20:59-72.

177. Peppard PE, Young T. Exercise and sleep-disordered breathing: an association independent of body habitus. Sleep. 2004;27(3):480-4.

178. Smeets RJ, Wittink H, Hidding A, Knottnerus JA. Do patients with chronic low back pain have a lower level of aerobic fitness than healthy controls?: are pain, disability, fear of injury, working status, or level of leisure time activity associated with the difference in aerobic fitness level? Spine (Phila Pa 1976). 2006;31(1):90-7. discussion 8.

179. Prasad B, Nyenhuis SM, Weaver TE. Obstructive sleep apnea and asthma: associations and treatment implications. Sleep Med Rev. 2014;18(2):165-71. 